\title{
Myopia Control: A Citation Network Study
}

\author{
Cesar Villa-Collar ${ }^{1}$, Cristina Alvarez-Peregrina ${ }^{1}$, Miguel Angel Sanchez-Tena ${ }^{1}$
}

${ }^{1}$ Universidad Europea de Madrid - School of Biomedical and Health Science, Madrid, Spain

Epub: June 21, 2020

\begin{abstract}
Background: According to the World Health Organization, myopia is already one of the major causes of vision impairment and blindness. It is predicted to affect almost a half of the world's population within the next years. A lot of researches around the world have been performed on myopia, there is no clear overview of these researchers. In this manuscript, we analyzed the main connections between the most cited researchers, to build a citation network to evaluate the impact of different authors, journals, and subjects in the field of myopia control.

Methods: A search using the keywords "myopia control" was made through Web of Science. Extracted data was analyzed using CitNetExplorer ${ }^{\circledR}$ software obtaining a visual evaluation of the most cited publications. A subnet analysis was made by adding the keywords "myopia control" AND ("orthokeratology" OR "corneal refractive therapy"), "myopia control" AND ("soft contact lens*" OR "multifocal contact lens*"), and "myopia control" AND "atropine". The most important publications of the network and subnetworks were analyzed using the "core" function.

Results: This study showed 228 references that generated 1087 citations across the network. 2013 was the most important year for myopia control, with most publications and citations. Optometry and Vision Science journal has published the most cited papers. Regarding the authors, Walline ranked the first of the most cited articles on myopia control.

Conclusion: This study analyzed the associations between the authors, journals and subjects in myopia control, highlighting the great importance of this area in the recent years. More than $50 \%$ of the papers in the network were published after 2013.

\section{KEY WORDS}

Myopia Control; Atropine; Atropine Sulphate; Contact Lens; Orthokeratology Citation Network; Historical Control Studies.

Copyright (C) 2020, Med Hypothesis Discov Innov Ophthalmol. This is an open-access article distributed under the terms of the Creative Commons Attribution-NonCommercial 4.0 International License (http://creativecommons.org/licenses/by-nc/4.0/) which permits copy and redistribute the material just in noncommercial usages, provided the original work is properly cited.
\end{abstract}

Correspondence to: Dr Cristina Alvarez-Peregrina PhD; Universidad Europea de Madrid, 28670 Villaviciosa de Odon, Madrid, Spain, E-mail: cristinaalvarezperegrina@gmail.com

How to cite this article: Villa-Collar C, Alvarez-Peregrina C, Sanchez-Tena MA, Myopia Control: A Citation Network Study. Med Hypothesis Discov Innov Ophthalmol. 2020; 9(3): 208-214.

\section{INTRODUCTION}

Recently there has been a significant worldwide increase in the number of people having myopia to the extent that it has become an epidemiological problem [1]. The prevalence of myopia increased from $10.4 \%$ in 1993 to $34.2 \%$ in 2016 [2]. The latest estimates show a rate close to $50 \%$ by 2050 [3]. Being able to reduce myopia progression has become a worldwide concern, especially for the parents of myopic children [4]. At the same time, there has been an evolution in methods to control this progression. Research on myopia has been increased in the recent years [5], driven by the diversity of the methods used in myopia control.

A citation network analysis gives more simple and visual information, providing a better understanding of the research conducted in a specific field. However, statistical analysis of the strength of the relationship between articles that are both cited by a third article can help researchers identify the intellectual basics of the discipline. The use of this citation analysis methodology will allow us to identify the most 
relevant authors, publications and journals. As far as their citation is concerned, the most important years for their publications, and the different clusters of study within a specific field are elucidated [6].

The aim of this study was to identify the most relevant research and different areas of study on myopia control. Through this kind of analysis, the most cited studies can be quantified.

\section{METHODS}

This bibliometric research was defined to clustering publications, based on their citation relations, and analyze the results of the clustering at individual publications' level.

The website used in this first bibliometric step was WEB OF SCIENCE, a Web technology-based platform that includes the references of the main scientific publications of any discipline of knowledge since 1945 [7]. Using remote download techniques, papers published between 1970 and June of 2019 were selected by entering the main descriptor: " myopia control ", limiting the field for the article, keywords and abstract, linked with the OR tab. All original articles, brief articles, reviews, editorials, letters to the editor, etc., were considered and duplicated documents were eliminated.

The file downloaded from Web of Science was analyzed using the CitNetExplorer ${ }^{\circledR}$ software, a software used to visualize and analyze the most important publications in a specific field and showing their relationships [8].

A quantitative analysis was made to show the total number of citations in the network in a given period. The attribute of CitNetExplorer ${ }^{\circledR}$ studied was the "citation score". This is a very useful tool in the citation network analysis. It allows quantifying internal connections between the authors, magazines and subjects through the publications within the network [9].

The subnet analysis could be performed by entering more keywords or using the software's cluster function [10]. Therefore, clusters are created according to the most frequent subtopics studied in the field [11].

In this study, the subnet analysis was made to analyze the different treatments for controlling myopia development. The keywords used in this subnet analysis were "myopia control" AND ("orthokeratology" OR "corneal refractive therapy"), "myopia control" AND ("soft contact lens*" OR "multifocal contact lens*"), and "myopia control" AND "atropine".
The most important publications of the network were also analyzed using the function "core". This function gives the percentage of publications with four or more citations within the network [6].

Finally, the analysis was supported graphically with VOSviewer $^{\circledR}$, a software tool for constructing and visualizing bibliometric networks. This software analyzes graphically the most cited articles and the clustering results obtained from CitNetExplorer ${ }^{\circledR}$. VOSviewer $^{\circledR}$ facilitates the analysis of clustering solutions. The same software was used to visualize the core function graph [12].

\section{RESULTS}

During the study period, 228 documents were published, generating 1087 citations within the network. Table 1 shows the 20 most cited publications. The most cited paper was written by Walline et al. [13], published in 2009, with a citation score of 68 . Figure 1 shows the network of 20 most cited articles about myopia control.

"Core Function" result is shown in Figure 2. One hundred and forty-eight publications had four or more citations, which represented $64.92 \%$. In this figure, each circle corresponds to an important paper represented by the last name of the first author and year of publication. The size of the circles corresponds to the number of times the paper has been cited. Finally, the colors of the map show the different clusters of publications created automatically by the software.

Analyzing the 20 most cited publications about myopia control showed that 8 were about orthokeratology, 6 about multifocal contact lenses, 3 meta-analyses or treatment reviews, one on ophthalmic lenses, one about rigid gas permeable lenses, and one about atropine. According to the abovementioned most cited publications and the knowledge about the most currently used treatments for myopia control that are defined in a review [14] and a meta-analysis, the results of orthokeratology, contact lenses, and atropine were as follows:

In the first case "myopia control" AND ("orthokeratology" OR "corneal refractive therapy"), 100 publications were found since 2004, generating 482 citations across the network. The abovementioned paper of Walline et al [13] published in 2009 was the most cited one. In this paper, the authors confirmed all the previous work on controlling myopia by fitting orthokeratology lenses. This network is shown in Figure 3. 
Table 1. Twenty Most Cited Papers From 1970 to 2019 in the Myopia Control Citation Network

\begin{tabular}{|c|c|c|c|c|}
\hline Authors & Paper title & Journal & Year & Citation \\
\hline Walline et al. & Corneal reshaping and myopia progression & Br J Ophthalmol. Sep; 93 (9): 1181-5 & 2009 & 68 \\
\hline Walline et al. & Multifocal contact lens myopia control & Optom Vis Sci. Nov; 90 (11): 1207-14 & 2013 & 52 \\
\hline $\begin{array}{l}\text { Santodomingo- } \\
\text { Rubido et al. }\end{array}$ & $\begin{array}{l}\text { Myopia control with orthokeratology contact lenses in } \\
\text { Spain: refractive and biometric changes }\end{array}$ & $\begin{array}{l}\text { Invest Ophthalmol Vis Sci. Jul; } 53 \text { (8): } \\
5060-5\end{array}$ & 2012 & 51 \\
\hline $\begin{array}{l}\text { Swarbrick et } \\
\text { al. }\end{array}$ & $\begin{array}{l}\text { Myopia control during orthokeratology lens wear in } \\
\text { children using a novel study design }\end{array}$ & Ophthalmology Tue; 122 (3): 620-30 & 2014 & 36 \\
\hline Edwards et al. & $\begin{array}{l}\text { The Hong Kong progressive lens myopia control study: } \\
\text { study design and main findings }\end{array}$ & $\begin{array}{l}\text { Invest Ophthalmol Vis Sci. Sep; } 43 \\
\text { (9): } 2852-8\end{array}$ & 2002 & 35 \\
\hline Kang et al. & $\begin{array}{l}\text { Peripheral refraction in myopic children wearing } \\
\text { orthokeratology and gas-permeable lenses. }\end{array}$ & Optom Vis Sci. Apr; 88 (4): 476-82 & 2011 & 33 \\
\hline Chen et al. & $\begin{array}{l}\text { Myopia control using toric orthokeratology (TO-SEE } \\
\text { study) }\end{array}$ & $\begin{array}{l}\text { Invest Ophthalmol Vis Sci. Oct; } 54 \\
\text { (10): 6510-7 }\end{array}$ & 2013 & 33 \\
\hline Huang et al. & $\begin{array}{l}\text { Efficacy Comparison of } 16 \text { Interventions for Myopia } \\
\text { Control in Children: A Network Meta-analysis }\end{array}$ & Ophthalmology Apr; 123 (4): 697-708 & 2016 & 32 \\
\hline Charm et al. & $\begin{array}{l}\text { High myopia-partial reduction ortho-k: a 2-year } \\
\text { randomized study }\end{array}$ & $\begin{array}{l}\text { Optom Vis Sci. Jun; } 90 \text { (6): 530- } \\
92011\end{array}$ & 2013 & 31 \\
\hline Walline et al. & Interventions to slow progression of myopia in children & $\begin{array}{l}\text { Cochrane Database Syst Rev. Dec 7; } \\
\text { (12):CD004916 }\end{array}$ & 2011 & 29 \\
\hline Aller et al. & $\begin{array}{l}\text { Myopia Control with Bifocal Contact Lenses: A } \\
\text { Randomized Clinical Trial }\end{array}$ & $\begin{array}{l}\text { Optom Vis Sci. } \\
\text { Apr; } 93 \text { (4): } 344-52\end{array}$ & 2016 & 29 \\
\hline Walline et al. & $\begin{array}{l}\text { A randomized trial of the effects of rigid contact lenses } \\
\text { on myopia progression }\end{array}$ & $\begin{array}{l}\text { Arch Ophthalmol. Dec; } 122(12): \\
1760.6\end{array}$ & 2004 & 28 \\
\hline Si et al. & Orthokeratology for myopia control: a meta-analysis & $\begin{array}{l}\text { Optom Vis Sci. } \\
\text { Tue; } 92 \text { (3): } 252-7\end{array}$ & 2015 & 28 \\
\hline Leung et al. & $\begin{array}{l}\text { Progression of myopia in Hong Kong Chinese } \\
\text { schoolchildren is slowed by wearing progressive lenses }\end{array}$ & Optom Vis Sci. Jun; 76 (6): 346-54 & 1999 & 25 \\
\hline Chia et al. & $\begin{array}{l}\text { Five-Year Clinical Trial on Atropine for the Treatment of } \\
\text { Myopia 2: Myopia Control with Atropine } 0.01 \%\end{array}$ & Ophthalmology. Feb; 123 (2): 391-9 & 2016 & 22 \\
\hline Aller et al. & $\begin{array}{l}\text { Bifocal soft contact lenses as a possible myopia control } \\
\text { treatment: a case report involving identical twins }\end{array}$ & Clin Exp Optom. Jul; 91 (4): 394-9 & 2008 & 18 \\
\hline Pauné et al. & $\begin{array}{l}\text { Myopia Control with a Novel Peripheral Gradient Soft } \\
\text { Lens and Orthokeratology: A 2-Year Clinical Trial }\end{array}$ & Biomed Res Tnt. 2015: 507572 & 2015 & 17 \\
\hline Cheng et al. & $\begin{array}{l}\text { Soft Contact Lenses with Positive Spherical Aberration } \\
\text { for Myopia Control }\end{array}$ & Optom Vis Sci.Apr; 93 (4): 353-66 & 2016 & 16 \\
\hline Holden et al. & $\begin{array}{l}\text { Myopia, an underrated global challenge to vision: where } \\
\text { the current data takes us on myopia control }\end{array}$ & Eye (Lond). Feb; 28 (2): 142-6 & 2014 & 15 \\
\hline Tarrant et al. & $\begin{array}{l}\text { Accommodation in emmetropic and myopic young } \\
\text { adults wearing bifocal soft contact lenses }\end{array}$ & $\begin{array}{l}\text { Ophthalmic Physiol Opt. Jan; } 28 \text { (1): } \\
62-72\end{array}$ & 2008 & 13 \\
\hline
\end{tabular}

The second search "myopia control" AND ("soft contact lens*" OR "multifocal contact lens*") produced 53 publications that generated 230 citations. In this case, the most cited also corresponded to Walline et al. [15], but on this occasion, it is their paper about myopia control with multifocal contact lenses published in 2013. This paper took the second place of 20 in the general "myopia control" network, and its authors concluded that the use of multifocal soft contact lenses reduced myopia progression by $50 \%$ and axial length by $29 \%$ over two years compared to a historical control group. However, the authors indicated the need for randomized clinical trials to confirm the data. The graph of this network is shown in Figure 4. Finally, in the third search ("myopia control" AND "atropine"), 42 publications were found that generated 75 citations across the network. In this case, the most cited paper was from Chia et al. [16], published in Ophthalmology in 2016. This paper ranked $15^{\text {th }}$ of the 20 most cited papers in the general "myopia control" network Table 1 . Its authors concluded that $0.01 \%$ atropine was effective in controlling myopia with fewer side effects on vision than other higher doses of the abovementioned medicine. The graph of this network is shown in Figure 5. 


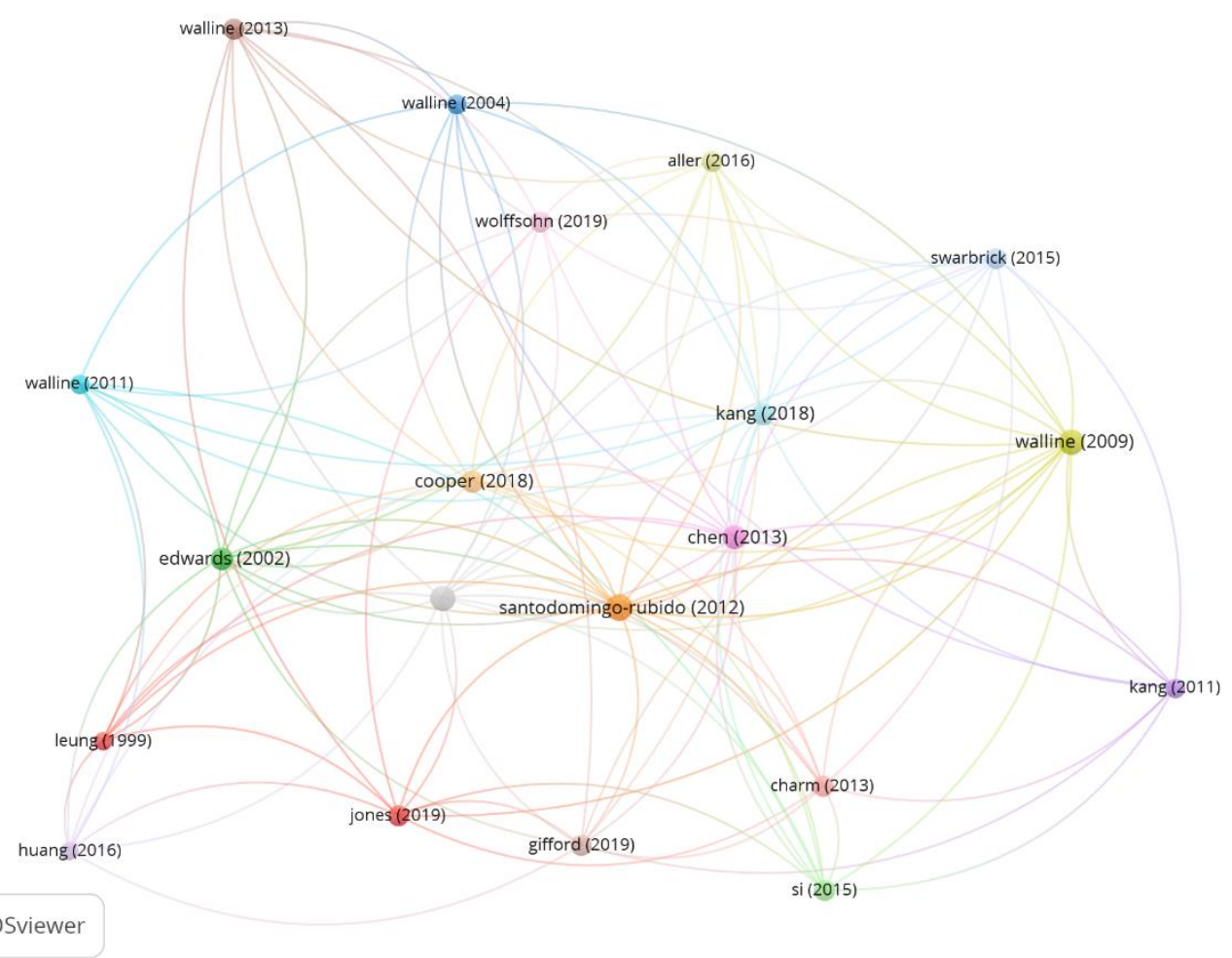

Figure 1. Network of the Twenty Most Cited Articles About Myopia Control.

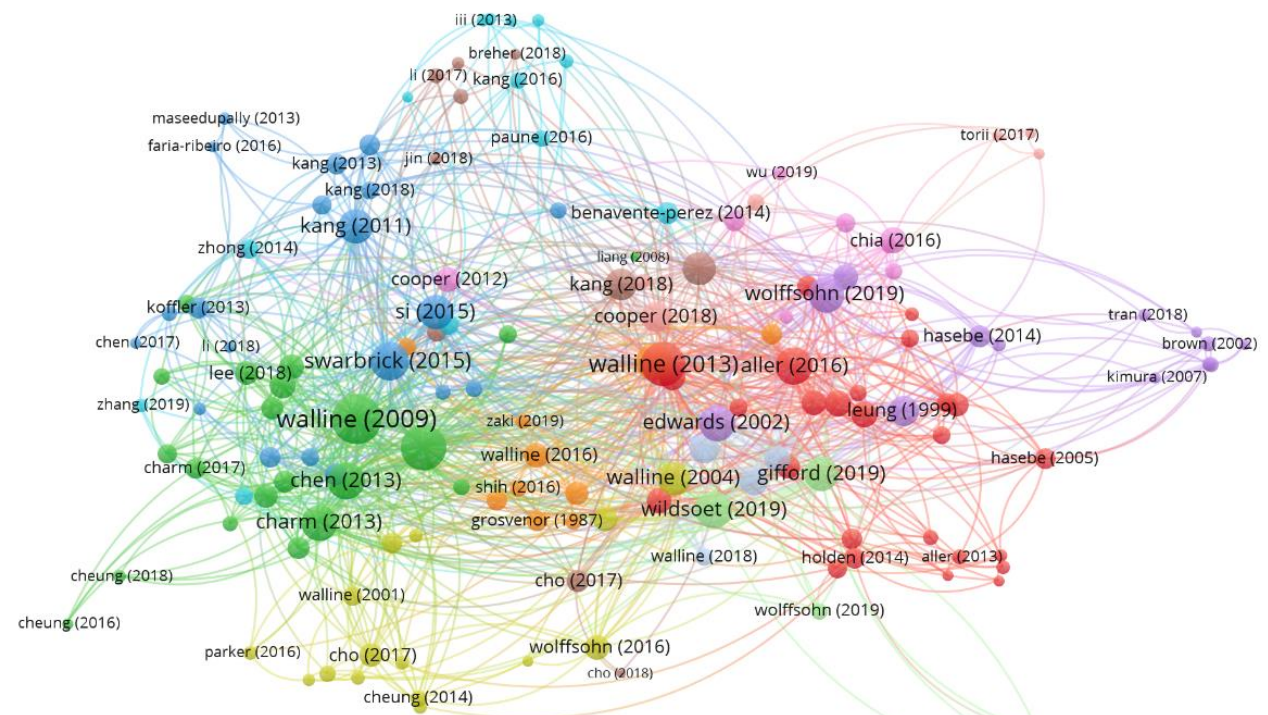

$\operatorname{garcia}(2017)$

\& Vosviewer

Figure 2. "Core function" of the Myopia Control Network. 


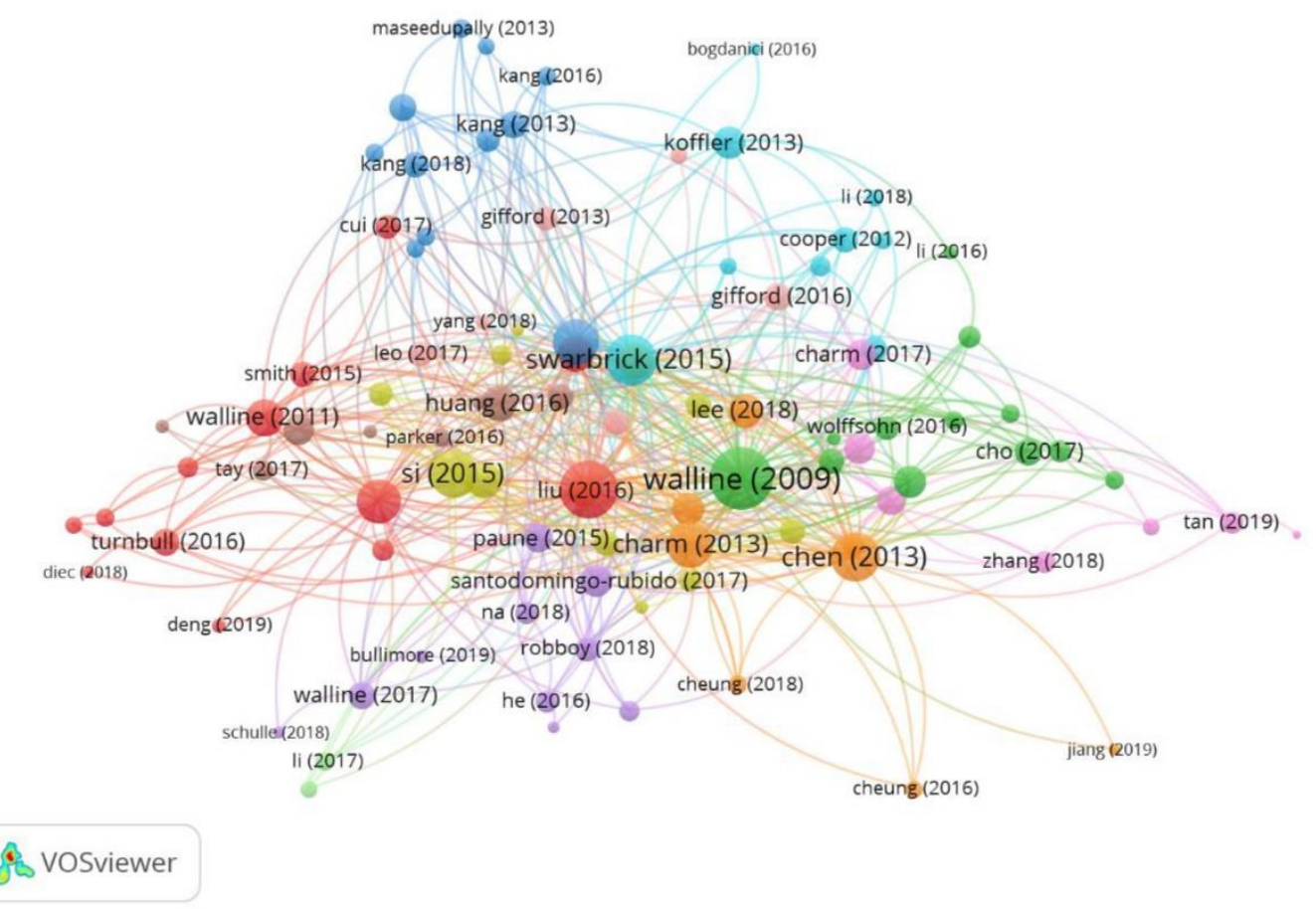

Figure 3. The Citation Network of "Myopia Control" and ("Orthokeratology" or "Corneal Refractive Therapy").

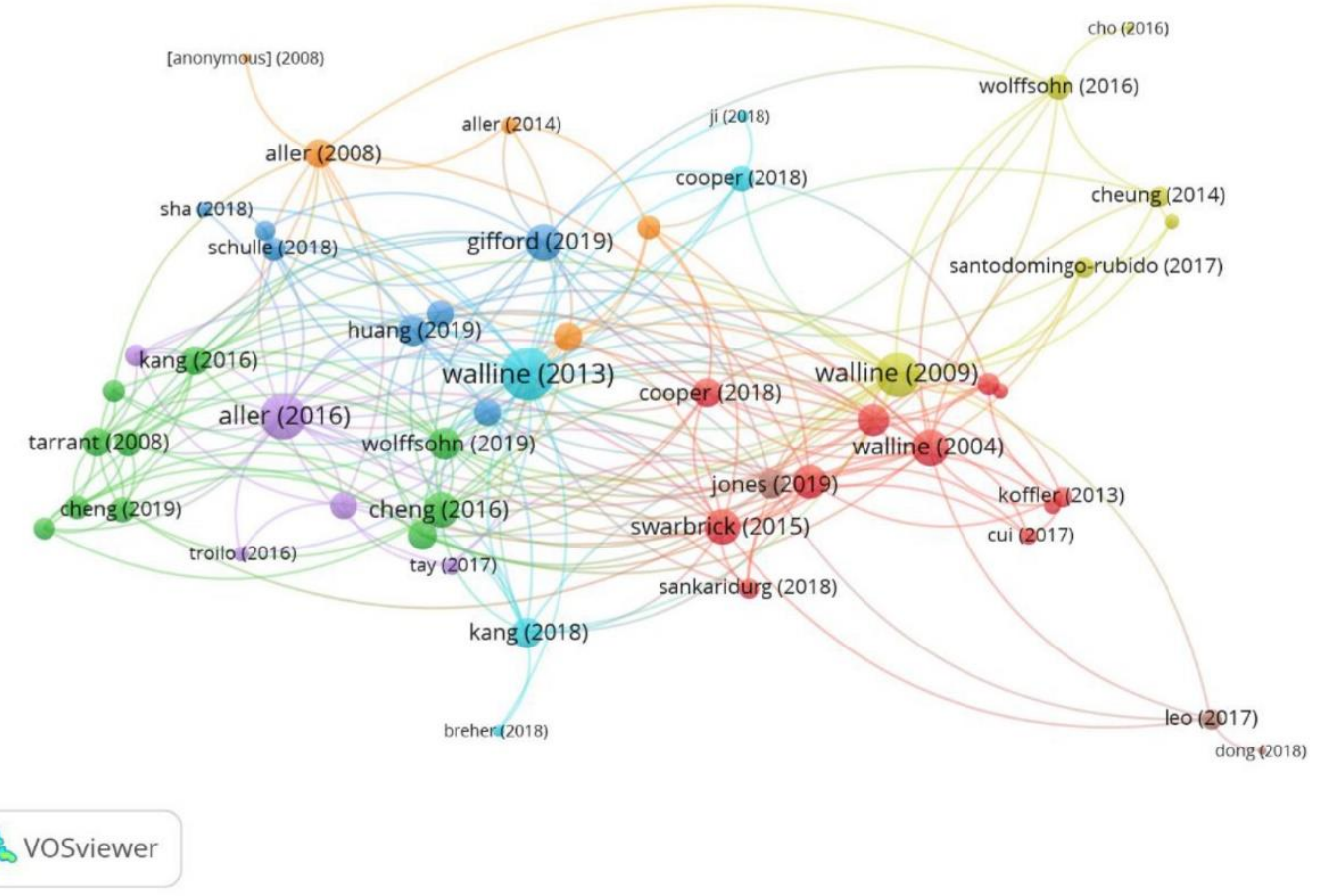

Figure 4. The Citation Network of "Myopia Control" and ("Soft Contact Lens" or "Multifocal Contact Lens").

Med Hypothesis Discov Innov Ophthalmol. 2020; 9(3) 


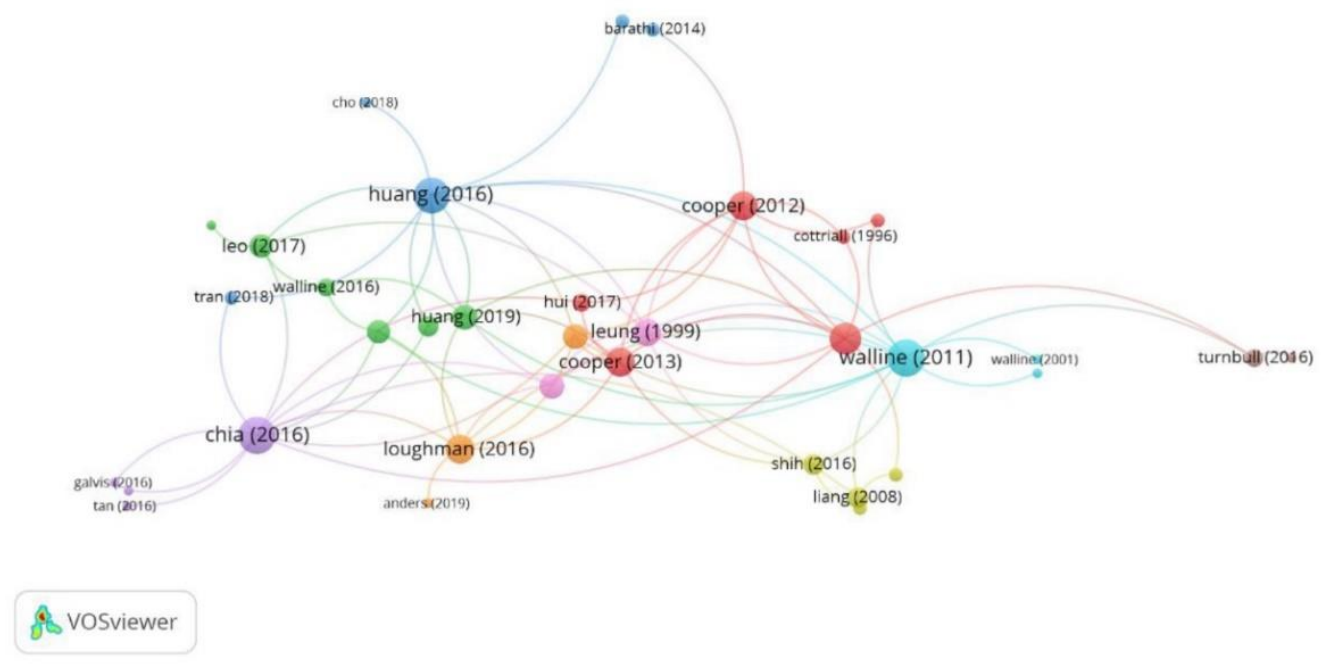

Figure 5. The Citation Network of "Myopia Control" and "Atropine".

\section{DISCUSSION}

This analysis shows the evolution of citation networks over the years. The network starts at 1970 because this is the year corresponding to the first published evidence to myopia control in the scientific literature. The 20 most cited papers in the network were published between 1999 and 2016. It is worthy to highlight the great importance of the research in myopia control in recent years. As the data reveals, more than $50 \%$ of the 20 papers most cited in the network published since 2013. The most productive year was 2016, with four papers within the 20 most cited ones in this field.

The number of citations of the 20 most cited papers varies between 13 and 68, with three papers being above the average (41 citations). Two of these three papers are about nocturnal orthokeratology and the other one about soft contact lenses for myopia control. $60 \%$ of the papers (12 articles) in the network are about these two topics. Regarding the journals in which the most cited papers have been published, seven were published in Optometry Vision Science (OVS) journal, three in Investigative Ophthalmology Visual Science (IOVS), and three in Ophthalmology. Reviewing MEDLINE within the study period, the number of papers published in these journals with the keyword "myopia control" was 125 in OVS, 231 in IOVS, and 1422 in Ophthalmology.

The authors of the three papers with more than 41 citations were Walline [13] , [15] and SantodomingoRubido [17]. In the analysis of the clusters about "myopia control" AND ("orthokeratology" OR "corneal refractive therapy"), "myopia control" AND ("soft contact lens*" OR "multifocal contact lens*") and myopia control with atropine, it is worthy to highlight the followings;

\section{Orthokeratology}

The 20 most cited papers in this subnetwork, which comprises a total of 100 papers, were published between 2004 and 2016. 2013 was the most productive year, with four publications. The number of citations varied between 10 and 53. The authors with more than 41 citations were Walline [13] and Santodomingo-Rubido [17].

The journals containing the most cited papers were the OVS with 8, the IOVS with 2, and the Ophthalmology with 2. In this case, the number of MEDLINE publications of those journals with the keywords "myopia control" and ("orthokeratology" or "corneal refractive therapy") were 10,4 and 2, respectively.

\section{Soft contact lens}

The 20 most cited papers in this subnetwork, including a total of 53 papers, were published between 2001 and 2019. In this case, the most productive years were 2016 and 2017 with 10 publications. The number of citations varied between 2 and 31 . The authors with publications of more than 20 citations, as an average, were Walline [15], Walline [13] an Aller [18].

The journals containing the most cited papers were the OVS with 8, the Clinical \& Experimental Optometry, the Contact Lens and Anterior Eye and Ophthalmic Physiological Optics with 2. In this case, the number of MEDLINE publications of those journals with the keywords "myopia control" and ("soft contact lens*" or "multifocal contact lens*") were $12,4,6$ and 6 , respectively.

\section{Atropine}

In this last subnetwork, containing 42 papers, the 20 most cited were published between 1999 and 2019. 2016 was 
the most productive year, with five publications. The number of citations were lower than the rest of clusters, varying between 1 and 12 . The authors whose publications had more than 10 citations were Chia [16], Walline [19], and Huang [14].

The journals containing the most cited papers were the OVS, Ophthalmology, and Eye \& Contact Lens, with 4, 3, and 2 papers, respectively. The number of MEDLINE publications of these journals with the keywords "myopia control" and "atropine" were 8, 76 and 4, respectively.

\section{CONCLUSION}

Myopia control is a very important field for researchers, with a very high number of publications and many connections among articles increasing in the recent years. This citation network analysis shows 2013 as a key year in this field. Besides, orthokeratology and soft contact lenses are the most productive research areas in myopia control. Regarding the authors, Walline ranked the first of the most cited articles on myopia control and the Optometry and Vision Science have published most cited papers.

\section{ETHICAL DECLARATIONS}

Ethical Approval: This is a scientometric study based on other published articles. No ethical approval is required.

Conflict of Interest: None.

\section{FUNDING}

The author(s) received no specific funding for this work.

\section{ACKNOWLEDGMENTS}

The authors thank Peter Bonney for English editing.

\section{REFERENCES}

1. Mitchell P, Hourihan F, Sandbach J, Jin Wang J. The relationship between glaucoma and myopia. Ophthalmology. 1999;106(10):2010-5. doi: 10.1016/s0161-6420(99)90416-5

2. Hashemi H, Fotouhi A, Yekta A, Pakzad R, Ostadimoghaddam H, Khabazkhoob M. Global and regional estimates of prevalence of refractive errors: Systematic review and meta-analysis. J Curr Ophthalmol. 2018;30(1):3-22. doi: 10.1016/j.joco.2017.08.009 pmid: 29564404

3. Holden BA, Fricke TR, Wilson DA, Jong M, Naidoo KS, Sankaridurg P, et al. Global Prevalence of Myopia and High Myopia and Temporal Trends from 2000 through 2050. Ophthalmology. 2016;123(5):1036-42. doi: 10.1016/j.ophtha.2016.01.006 pmid: 26875007
4. Walline JJ. Myopia Control: A Review. Eye Contact Lens. 2016;42(1):3-8. doi: 10.1097/ICL.0000000000000207 pmid: 26513719

5. Villa-Collar C, Alvarez-Peregrina C, Hidalgo Santa Cruz F, Povedano-Montero FJ. Bibliometric Study of Scientific Research on Overnight Orthokeratology. Eye Contact Lens. 2018;44(5):344-9. doi: 10.1097/ICL.0000000000000545 pmid: 30148458

6. Van Eck N, Waltman L. CitNetExplorer: A new software tool for analyzing and visualizing citation networks. Journal of Informetrics. 2014;8(4):802-23.

doi: https://doi.org/10.1016/j.joi.2014.07.006

7. Web of Scince [cited 2020 May 20]. Available from: https://clarivate.com/webofsciencegroup.

8. CitNetExplorer. Analyzing citation patterns in scientific literature. [Citation Network Explorer Web Site] 2019 [February 8, 2019]. Available from: http://www.citnetexplorer.nl.

9. Torres-Salinas D, Delgado López-Cózar E, JiménezContreras E. Redes de citación de las revistas españolas de Ciencias Sociales 1994-2006. Revista española de Documentación Científica. 2009;32(2):34-50. doi: 10.3989/redc.2009.2.686

10. Sanchez-Tena M, Alvarez-Peregrina CC, Villa-Collar CC. Dry Eye Analysis: A Citation Network Study. J Ophthalmol. 2019;2019:3048740. doi: 10.1155/2019/3048740 pmid: 31485342

11. González C. Citation and social network analysis for the study of the use of journals in research centers Brasilia2009 [updated 29 September 2019; cited 2009]. Available from: http://www.scielo.br/pdf/ci/v38n2/04.pdf.

12. van Eck NJ, Waltman, L. . Software survey: VOSviewer, a computer program for bibliometric mapping. Scientometrics. 2010;84:523-38. doi: https://doi.org/10.1007/s11192-009-0146-3

13. Walline JJ, Jones LA, Sinnott LT. Corneal reshaping and myopia progression. $\mathrm{Br} J$ Ophthalmol. 2009;93(9):1181-5. doi: 10.1136/bjo.2008.151365 pmid: 19416935

14. Huang J, Wen D, Wang Q, McAlinden C, Flitcroft I, Chen H, et al. Efficacy Comparison of 16 Interventions for Myopia Control in Children: A Network Meta-analysis. Ophthalmology. 2016;123(4):697-708. doi: 10.1016/j.ophtha.2015.11.010 pmid: 26826749

15. Walline JJ, Greiner KL, McVey ME, Jones-Jordan LA. Multifocal contact lens myopia control. Optom Vis Sci. 2013;90(11):1207-14. doi: 10.1097/OPX.0000000000000036 pmid: 24061152

16. Chia A, Lu QS, Tan D. Five-Year Clinical Trial on Atropine for the Treatment of Myopia 2: Myopia Control with Atropine $0.01 \%$ Eyedrops. Ophthalmology. 2016;123(2):391-9. doi: 10.1016/j.ophtha.2015.07.004 pmid: 26271839

17. Santodomingo-Rubido J, Villa-Collar C, Gilmartin B, Gutierrez-Ortega R. Myopia control with orthokeratology contact lenses in Spain: refractive and biometric changes. Invest Ophthalmol Vis Sci. 2012;53(8):5060-5. doi: 10.1167/iovs.11-8005 pmid: 22729437

18. Aller TA, Liu M, Wildsoet CF. Myopia Control with Bifocal Contact Lenses: A Randomized Clinical Trial. Optom Vis Sci. 2016;93(4):344-52. doi: 10.1097/OPX.0000000000000808 pmid: 26784710

19. Walline JJ, Lindsley K, Vedula SS, Cotter SA, Mutti DO, Twelker JD. Interventions to slow progression of myopia in children. Cochrane Database Syst Rev. 2011(12):CD004916. doi: 10.1002/14651858.CD004916.pub3 pmid: 22161388 